\title{
A SIMPLIFIED PROCEDURE FOR MAJOR \\ THOROUGHFARE PLANNING IN SMALL \\ URBAN AREAS
}

DECEMBER 1972 - NUMBER 49

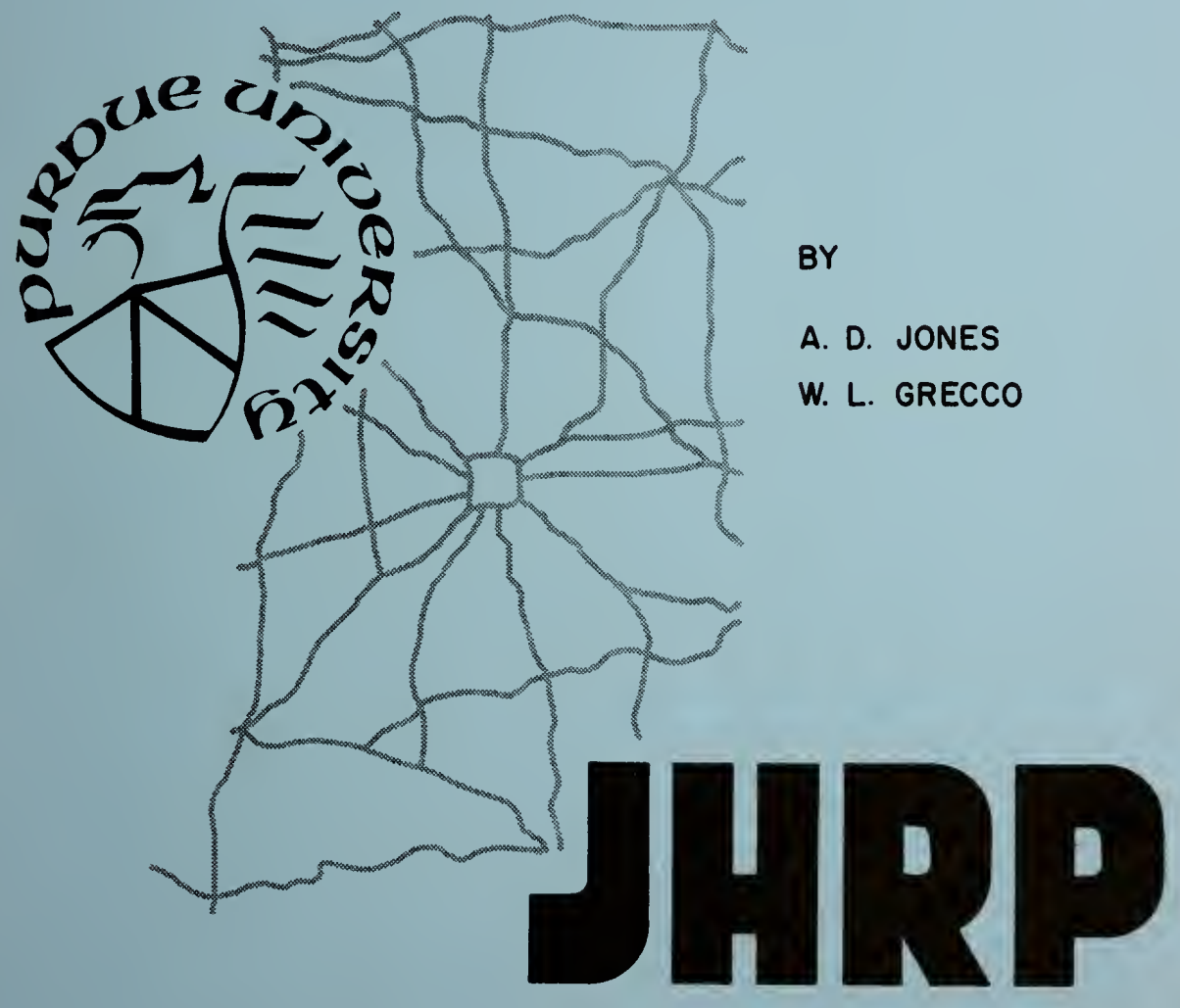

JOINT HIGHWAY RESEARCH PROJECT PURDUE UNIVERSITY AND

INDIANA STATE HIGHWAY COMMISSION 

A SIMPLIFIED PROCEDURE FOR MAJOR THOROUGHFARE PLANNING IN SMALL URBAN AREAS

TO: J.F. McLaughlin, Director Joint Highway Research project

FROM: H. I. Michae1, Associate Director Joint Highway Research Project
December 28,1972

Project: $C-36-69 D$

File: $\quad 3-7-4$

The attached Technical Paper "A Simplified Procedure for Major Thoroughtare Planning in Small Urban Areas" by A. D. Jones, Graduate Instructor in Research, and Professor W. L. Grecco is submitted for approval of presentation and publication. The paper is schedulea for presentation at the 1973 Annual Meeting of the Highway Research Board in January.

The Paper is a summary of a Final Report of the same title submitied on a porcion of the HPR Part I Research study titled "An Investigation of Major Aspects of the Urban Transportation Planning Process". The Final Report was accepted by FHWA as documertation of the research performed but with a number of comments and reservations and a request that some re-evaluation be done. This is being done but as of tinis date, the Fecieral Highway Administration does not subscribe to the findings and conclusions.

The Paper is submitted to the Board for approval of presentation and publication. It will also be forwarded for review, comment and similar approval to the ISHC and FHWA.

Respectfully submitted,

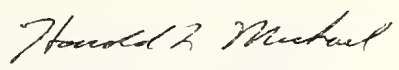

Harold I. Michael Associate Director

HLM : ms

$\begin{array}{lll}\text { cc: W. I. Dolch } & \text { M. I. Hayes } & \text { C. F. Scholer } \\ \text { R. L. Eskew } & \text { C. W. Lovell } & \text { M. B. Scott } \\ \text { W. H. Goetz } & \text { G. W. Marks } & \text { J. A. Spooner } \\ \text { M. J. Gutzwiller } & \text { R. D. Miles } & \text { N. W. Steinkamp } \\ \text { G. K. Hallock } & \text { J. W. Miller } & \text { H. R. J. Walsh } \\ \text { R. H. Harrell } & \text { G. T. Satterly } & \text { E. J. Yoder }\end{array}$




\title{
Technical paper
}

A SIMPLIFIED PROCEDURE FOR MAJOR THOROUGHFARE PLANNING IN SMALL URBAN AREAS

\author{
by \\ Andrew D. Jones \\ Graduate Instructor \\ and \\ William L. Grecco \\ Research Engineer \\ Joint Highway Research Project \\ Project No.: $C-36-69 \mathrm{D}$ \\ File No.: $3-7-4$ \\ Prepared as Part of an Investigation \\ conducted by \\ Joint Highway Research Project \\ Engineering Experiment Station \\ Purdue university \\ In cooperation with the \\ Indiana state Highway Commission \\ and the \\ U.S. Department of Transportation \\ Federal Highway Administration
}

The opinions, findings and conclusions expressed in this publication are those of the authors. The Federal Highway Administration does not subscribe to the findings and conclusions of this paper.

Purdue university

West Lafayette, Indiana

December 28,1972 
Digitized by the Internet Archive in 2011 with funding from

LYRASIS members and Sloan Foundation; Indiana Department of Transportation

http://www.archive.org/details/simplifiedproced7249jone 


\section{A SIMPLIFIED PROCEDURE FOR MAJOR THOROUGHFARE PLANNING}

IN SMALL URBAN AREAS

A. D. Jones, Greduate Instructor, Joint Highway Research Project, Purdue University

W. L. Grecco, Research Engineer, Joint Highway Research Project, Purdue University

\section{INFORMATIVE ABSTRACT}

The purpose of the research project was to develop a simplified procedure for major thoroughfare planning in small urban areas. Previously developed corridor growth factor models for developing future estimates of internal traffic in small urban areas were tested, modified and refined using Lafayette, Indiana data.

Regression models to provide data usually obtained by use of external cordon surveys were developed. External survey reports from thirty-six cities in fourteen states, ranging in population from ten thousand to ninety thousand, provided the majority of the data utilized. Alternate procedures for providing the external survey information, based on use of historical data from the subject city, were also developed.

The completed procedure provides forecasted traffic volumes within the accuracy necessary for major thoroughfare planning in small urban areas at 
lower cost and with a level of sophistication that will permit application by personnel usually available in small communities.

The feasibility of the complete procedure for providing the required traffic volume for major thoroughfare planning in small urban areas was demonstrated in Columbus, Indiana.

\section{INTRODUCTION}

The continuing planning process developed as provided by the Federal Ald Highway Act of 1962 was somewhat preclse and detalled in the stated requirements. A complete land use inventory, an inventory of existing physical facilities, an inventory of population and economic information, a review of existing zoning and subdivision regulation ordinances, an inventory of parking facilities and usaze, and a complete inventory and study of all other aspects pertaining to or connected with existing traffic was required. In addition to requiring the detalled inventories, the manner in which this information would be obtained was carefully outlined. A home interview orlgin-destination survey and an external cordon survey were specifically required. With the information from the external survey and other collected data, forecasts of future traffic volumes were made and total future trip generation by traffic zone within the study area determined. Through the use of computers, these future trips are distributed between the various traffic zones and finaly the total trips between zones are assigned to a mathematical representation of the major arterial network. Through this process the planners are able to determine the segments of the transportation system requiring either improvement or further planning for development of complete new segments to handle forecasted traffic for the target year. This is accomplished by comparing the assigned traffic to the existing capacity of the individual segments of the system. 
Techniques specifically designed to accomplish the same objectives for the smaller urban areas as for these larger studies have not been developed and tested. In general, especially in the 25,000 to 50,000 population range, It has been the practice to assume that the same studies and depth of detall as used in the larger areas were an absolute necessity. This of course means that in gmaller urban areas, to ensure statistically sound sampling, a much higher overall sample percentage is necessary for the home interview origindestination survey. In addition, a staff to successfully complete a transportation study requires highly qualified professional and technical personnel. The required professional staff for a sinall urban area will be almost as large as a staff for a larger urban area. The end result is that even if a competent staff were available to complete a transportation study for a small urban area, the cost will be much higher on a per capita basis than for a large urban area.

An additional major disadvantage of the detailed procedures followed in larger areas is the length of time required to complete such a comprehensive study. The initial data collection phase of a study will usually require a minimum of two years when using established procedures in any urban area. In addition, to attain the maximum benefits from such studies they should be reviewed and updated every five years as a minimum.

In the smaller urban areas of 5,000 to 50,000 population there are always many existing minor transportarion problems. These will become greater as the area grows and auto registrations increase. These problems can be alleviated by proper planning in the majority of cases even though such planning is not presently required by Federal legislation.

For the purposes of this study a small urban area will be defined as a geographically separate urban area. The size will be limited to less than 
100,000 population. Public transportation in such areas usually is nonexistent or at best provides transportation for a small portion of the population, therefore study procedures for this area will not be included. This is not to imply that smell urban areas can ignore the need to plan for a proper transit system.

A simplified planning procedure for major thoroughfare planning, developed and designeâ specifically to satisfy the requirements of small urban areas, is needed. The procedure must be easily applied by the type of personnel usually avallable at the municipal level of government, must require a small budget, and must produce results with the degree of accuracy necessary for sound thoroughfare planning.

The utilization of the existing city personnel would accomplish a multpurpose objective. First, the completion or the study by the local people would enhance the possibility of developing the all important continuing planuing process. Second, this type of procedure would permit maximum efficiency and econory, allowing city personnel to complete the required data collection during normal slack periods in their regular routine. Third, and possibly most important, the involved personnel w1ll gain an overall knowledge of the community and its traffic and transportation problems. The problem was approached with the above criteria as a guide.

French's (3) recently completed research study utilized data that are readily available in smell areas in order to develop simple models for deriving internal-internal traffic volumes on arterial streets in small urban areas. He used only three inciependent variables in his models which required collection of data. These variables were dwelling units, retail employment and total employment per corridor. The procedure also required delineating traffic corridors, establishing the limits of the central business district "numbers in parentheses refer to items in List of References 
and its environments and determining an external cordon line. The existing trafic volumes at each intersection of a major arterial with the corridor boundary was also required. All of the required information for the above models are readily available in all areas or easily obtainable from uncontrolled eerial photography such as flown by the U. S. Department of Agriculture, and other sources such as the state employment office, etc.

\section{CONCEPTUALIZATION}

In the larger urban areas the shear magnitude of the component parts of the transportation system and interactions of the many attracting forces or traffic generators make the problem impossible for the planners to mentally visuzlize. As a result a step by step planning process is required that includes data collection, assimilation and summarizing of the data with the use of computers. In this manner the individual components may each be carefully analyzed separately and then combined in any selected manner for analysis of alternate systems. However, this procedure is costly and is not necessary for transportation planning in smaller urban areas.

The majority of the small urban areas in this country have experienced a modified sector and concentric circle growth pattern. The central business district remains as the major traffic generator in the community and traffic corridors radiate outward from this center. If major shopping centers exist, they are usually located on the radial arterial streets and their size, even though they may be substantial, do not compare to the size of the central area; therefore their influence is subsidiary to the central area.

The traffic corridor concept of thoroughfare planning is not new. In fact, many transportation planners still feel this approach to the solution of the problem of providing an adequate transportation system is superior to 
a zone by zone enalysis even in this day of third generation computers. Using the corridor technique requires that both the capacity of the available thoroughfares and the forecasted future traffic volumes be determined by corridor. The traffic corridor concept is accepted in principle by all planners who utilize computer capacity-restrained-traffic assignment packages in transportation planning. This particular theory of assignment provides for a reduction in link speed when the assigned volume reaches a predetermined level, with this level being based on the level of service concept of capacity. The reduction in link speed forces computation of new zone to zone minimum paths or trees and new assignment of trips. This effectively distributes trips over a number of arterial streets serving the same basic traffic novement and provides in essence a corridor assignment. In many cases the reasons for traveller preference for one arterial over another in a corridor may be a slight travel time difference or other factor that can be readily rectified or which becomes nonexistent as volumes increase.

Future desfre or demand trafic volumes are necessary for each corridor to permit plenning for improvements to handle the demand within the time constraint established. French proposed that this future traffic volume could be obtained by multiplying the existing traffic volumes by a growth factor ( 3 ). The growth factor was based on growth of the "sctivities" in the corridor. Comparison of the streets capacities to forecasted volumes can then provide an estimate of system deficiencies.

\section{PROCEDURES}

The entire procedure is predicated on the assumption that the existing travel patterns in the community will remain stable over time. This is considered a reasonable assumption. It can be noted that even in the very large 
cities the basic travel patterns remain substantially the same except for clrcuitous travel over routes provided by controlled access facilities that tend to encourage such travel. In the small cities the growth is usually an extension along present patterns. To disrupt or change the basic travel patterns in a small city would require the elimination of a large portion of the existing street network. This is not likely to occur.

The procedure developed considers external and internal traffic separately and each will be discussed separately herein.

\section{Corridor Identification}

$\Lambda$ corridor may be defined as an area between traffic divides and representing the area producing trips served by the one or more basically parallel major streets in the area. The orlentation of the corridor in small urban areas would be basically orlented toward the central area because of its predominance as a generator. With a knowledge of the local travel habits, supplemented by aerial photographs, street classiffcations, land use maps, and a traffic volume map, the corridor limits may be determined. The corridor boundary should be equidistant between arterlals unless physical constraints dictate otherwise. Corridors may overlap with separate corridors identified on circumferential or cross routes.

To select corridors first requires delineation of the central area. This central area would include the CBD "core" and would generally include the "frame" of the CBD. Specifically, the central area would begin at the point where radiel corridors and the arterial streets serving the corridors merge and lose their individual identity. Usually the merging movement would be served by cross routes bordering the CBD providing for disbursement of trafIf to the scattered destinations. 
Traffic entering small cities is composed of varying percentages of external-internal and external-external traffic. Generally, the composition and magnitude of this traffic is determined by an external cordon survey.

It was determined that there were five different items in external traffic information requiring procedures to be developed for application in the planning. These were as follows:

1. Method of forecasting total external traffic volumes.

2. Method of allocating the total external traffic to each external cordon crossing.

3. Method of determining the amount of the forecasted total external traffic that is external-internal traffic volumes.

4. Method of allocating the external-internal traffic volumes to each external cordon station.

5. Method of determining the amount of the total external-internal traffic volumes that is the external-internal traffic destined to the central area.

Each of the above will be discussed separately.

There are two separate feasible procedures to follow for determining the total external traffic and the components of external-external and external-intemal traffic necessary for the simplified procedure for major thoroughfare planning. The procedure wlll be selected on the basis of the available information:

1. A previous external cordon survey study for the area is available.

2. Traffic volumes from a past year are the only avallable information at each cordon station. 
External Report Available

Total External Crossings. With an external survey report avallable the procedure is greatly simplified. A growth factor based on the increase in vehicle registretion should be adequate for forecasting to the future. A calibration period using a growth factor based on five to ten years should provide a check on the accuracy of the procedure. To test this assumption, fifteen cities in Indiana were selected for a data set. Traffic volumes on an external cordon around each city were obtained for two points in time which were not less than five and preferably ten to twenty years apart. The cordon Iine was established at a point that included the urban area for both years and where an Inälana count station was located. A regression analysis was made using the base year total external traffic volumes multiplied by a growth factor representing the increase in county vehicle registration for the period between the two points as the independent variable. The observed total external traffic volume for the later year was used as the dependent variable. The results of the regression analysis are presented in figure 1 and Table 1.

Allocation of Total Externel Volumes Between Cordon Stations. To develop a model for allocating total external traffic between stations, eight cities with external survey reports avallable for two points in time were used for the investigation. Data from a total of seventy-two external cordon crossings In the elght cities were utilized in a simple regression procedure. This technique for establishing the correlation between the variables was selected because of simplicity while at the same time being adequate. A statistical test was made that the percent of the total traffic crossing at each of the external cordon station remalns constant over time. As a test the percentages of 


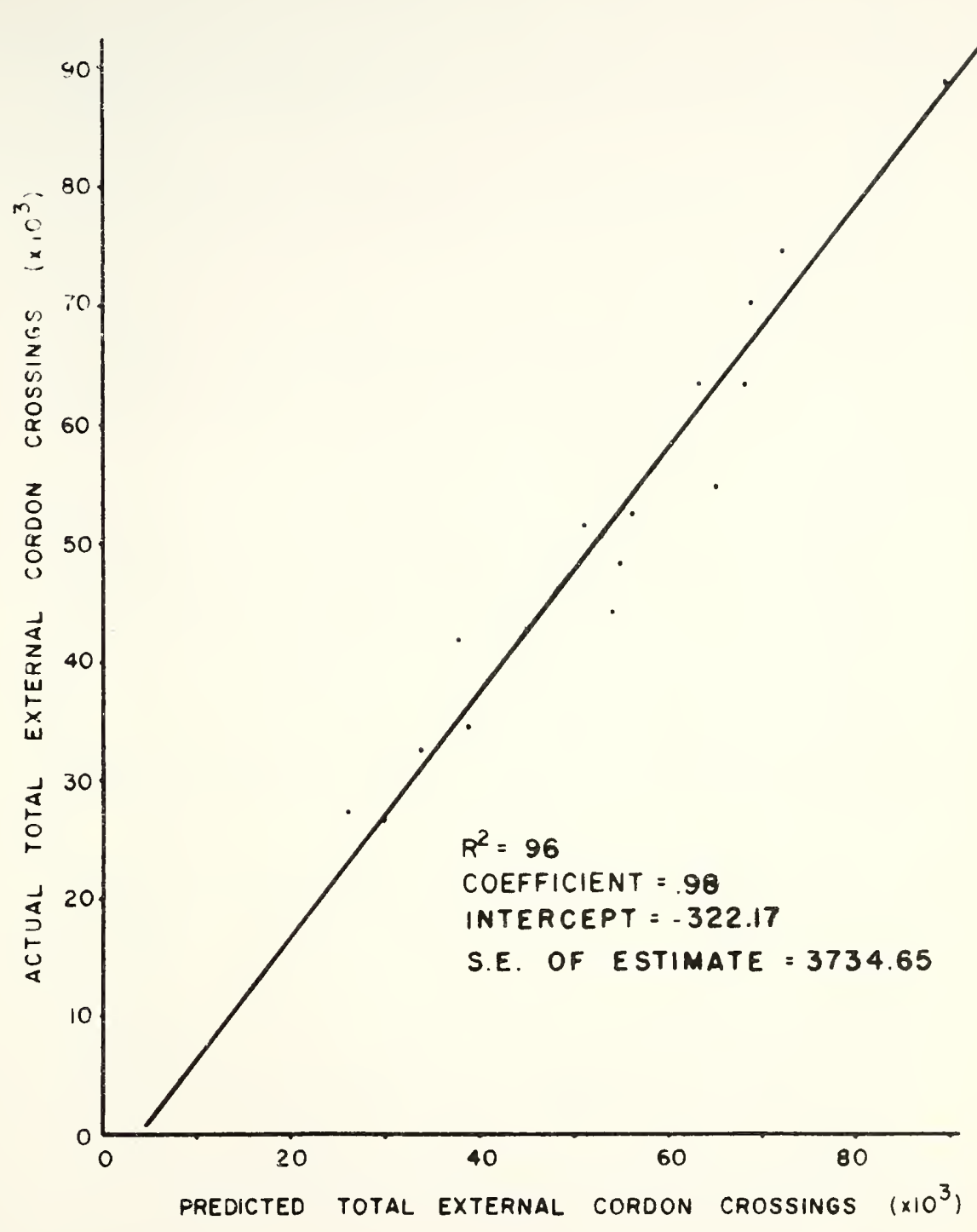

FIGURE I. COUNTY VEHICLE REGISTRATION INCREASE AS GROWTH FACTOR FOR EXTERNAL TRIPS 


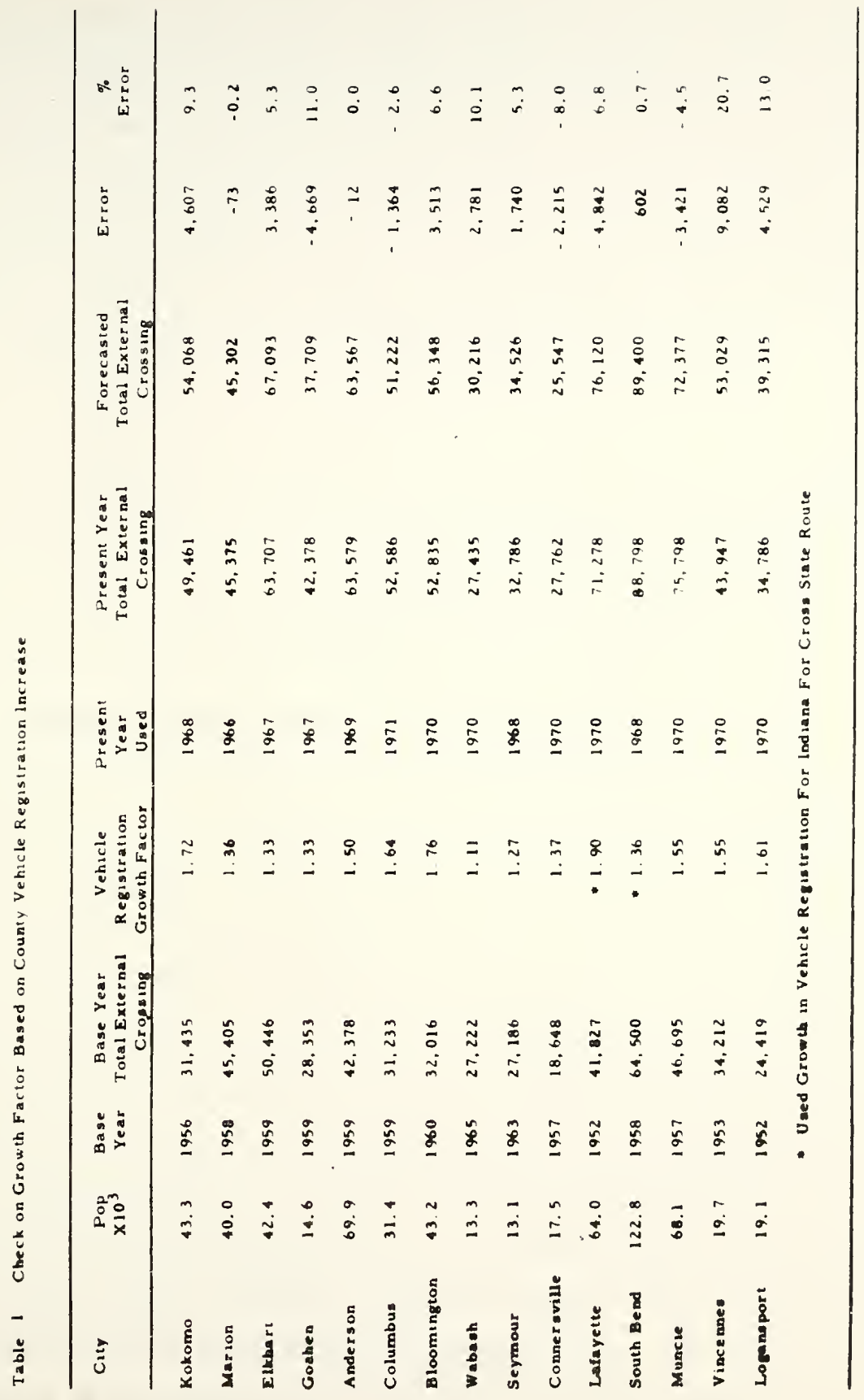


total traffic crossing at each station from the base year reports were used for the dependent or response variable and the percentages of total traffic crosilng at each station in the later reports were used for the independent variable. Values for stations in each city were computed in addition to a regression on a combined sample of all seventy-two crosings in the elght cities. The results of the analysis were examined to evaluate the comparison. Two null hypothesis were tested in each model as follows:

$$
\begin{aligned}
& \text { a. } H: B_{0}=0 \\
& \text { b. } H: B_{1}=1.00
\end{aligned}
$$

The first hypothesis tests that the intercept value is equal to zero while the second hypothesis tests that the regression coefficlent is equal to 1.00 . In eal models neither hypothesis could be rejected at the $\alpha=.05$ level. The results of the aralysis are shown in Figure 2.

Split Between External-External and External-Internal. With a past external survey aveilable for the city, the percentagesavallable for the city, the percentages of the total external-internal cordon crossings at each station as existed is probably the best estimate of the percentage of the total externalInternal cordon crossings for the study year; however, a procedure to provide this information where a report is not avallable will be presented later. A regression technique was used to test the sssumption that the percentage of the external-internal traffic crossing the external cordon at each cordon station was the same as the percentage of the total external traffic crossing at that same station. Twenty-seven survey reports were used for this phase of the investigation consisting of two hundred and thirty-two independent cordon crosilng stations. Values were computed for data for each clty in addition to the regression on the comblned sample. For this regression analysis the percentage of the total external cordon crossings at each cordon 


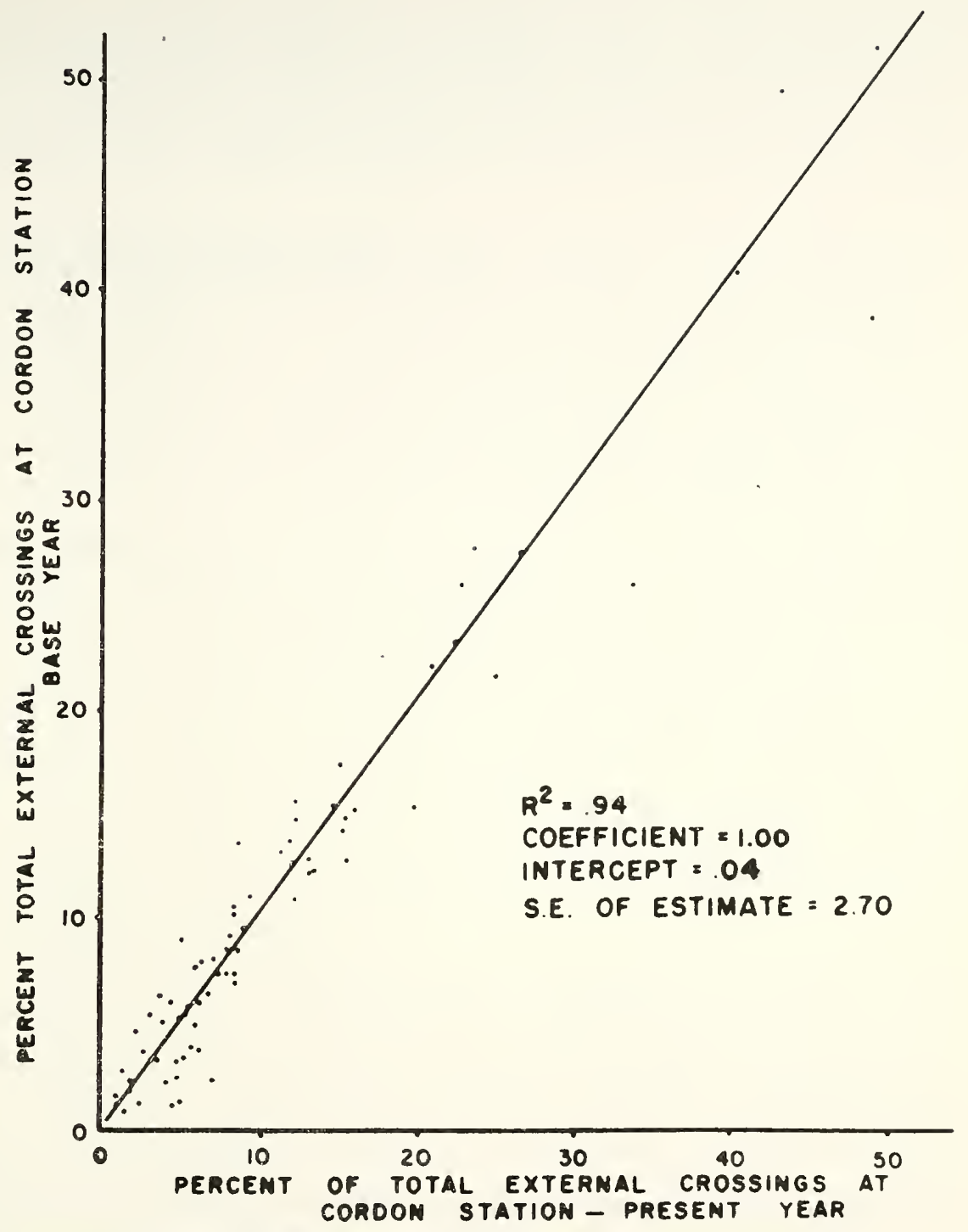

FIGURE 2. PERCENT OF TOTAL EXTERNAL CROBSINGS AT CORDON STATION IN DASE YEAR V. PERCENT EXTERNAL CROSSINGS AT CORDON STATION IN PRESENT YEAR 
station was used $a s$ the dependent or response variable. The percent of the total external-internal traffic at each cordon crosing was used as the independent variable. Table 2 and Figure 3 present the results of this analysis.

Determining Total External-Internal Volume. The split of the total external traffic volume into the two components, external-external and externalinternal traffic volumes, is required for the simplified planning procedure. If a previous external cordon survey has been completed, the percentage split at each station then provides the best estimate of the present split.

External-Internal Traffic to CBD. The final step necessary to provide a complete package for the simplified planning procedure is to determine a means of establishing the percentage of the external-internal trips at each external cordon station that are destined to the central area or to the screenline where the radial corridors merge and lose identity. Employment has been shown to be a very strong trip indicator in other studies and a simplified distribution method using employment, not requiring computer iterations for application, was developed.

Eleven study reports containing detalled employment data and trip information by traffic zones were utflized as the data source for this phase of the investigation. Cities included are shown in Table 3. Identification of a central area was inftialiy required. For this study the central area was defined as the CBD and the contiguous traffic zones where the total employment exceeded the number of residents.

The response variable of the regression analysis was the percent of external-internal trips destined to the Central Area. The independent variable was the percent of the total employment in the Central Area. The $R^{2}$ was .75 , 
Table 2 External Volume Vs. External-Internal Volume Model

\begin{tabular}{|c|c|c|c|c|c|c|}
\hline City & $\begin{array}{l}\text { Sampl } \\
\text { Size }\end{array}$ & le Intercept & $\begin{array}{l}\text { Reg. } \\
\text { Coeff. }\end{array}$ & $\begin{array}{l}\text { S. E. of } \\
\text { Est. }\end{array}$ & F Value & $R^{2}$ \\
\hline Independence, Kansas & 10 & .02 & 1.00 & 1.14 & 719.54 & .99 \\
\hline Big Rapids, Mich. & 6 & -4.36 & 1.26 & 2.42 & 206.11 & .98 \\
\hline Richmond, Ky. & 7 & -5.28 & 1. 38 & 3.27 & 90.08 & .95 \\
\hline Campbellsville, Ky. & 8 & -.81 & 1.07 & .92 & 274.06 & .98 \\
\hline Bonham, lexas & 6 & -1.23 & 1.07 & 3.60 & 36.7 & 90 \\
\hline Center, I exas & 8 & .48 & .96 & 1.83 & 21.54 & .78 \\
\hline New Castle, Penna. & 12 & -.00 & 1.00 & 1.57 & 87.72 & 90 \\
\hline Vincennes, Ind sana & 13 & -.03 & 1.01 & 2.54 & 113.44 & 91 \\
\hline Bay City, Mich. & 6 & -3.54 & 1.21 & 5.14 & 9.71 & 71 \\
\hline Ann Arbor, Mich. & 5 & 2.65 & .87 & 471 & 32.74 & 92 \\
\hline Bowling Green, Ky. & 10 & -2.20 & 1.22 & 2.48 & $140 \quad 91$ & .95 \\
\hline Junction City, Kansas & 11 & 1. 48 & .84 & 3.76 & 134.93 & .94 \\
\hline Brownwood, Texas & 9 & -.98 & 1.09 & 1.27 & 510.60 & .99 \\
\hline Somerset, Ky. & 9 & -1.35 & 1.12 & .91 & 997.01 & .99 \\
\hline Childress, Texas & 7 & -3.92 & 1.27 & 2.68 & 165.96 & .97 \\
\hline Bay City, Texas & 7 & -.21 & 1.02 & 1.27 & 651.34 & 94 \\
\hline Athens, Texas & 9 & -.60 & 1.05 & 1.00 & 380.05 & .98 \\
\hline Caruthersville, Missour & $r 24$ & 2.56 & .90 & 2.63 & $188 \quad 54$ & .99 \\
\hline Hannibal, Missour & 9 & -.68 & 1.06 & 1.36 & 440.44 & 48 \\
\hline Commerce, Texas & 6 & -.88 & 1.05 & 2.19 & 113.80 & .97 \\
\hline Blytheville, Ark. & 8 & -.09 & 1.01 & .39 & 4507.47 & 1. 00 \\
\hline Borger, Texas & 6 & 1.53 & .91 & 1. 18 & 347.64 & .99 \\
\hline Cynthiana, Ky. & 6 & -.69 & 1.04 & 3.09 & 80.51 & .95 \\
\hline Kinston, N.C. & 13 & -.05 & 1.01 & 1.93 & 85.50 & .89 \\
\hline Charlotteville, Vir. & 11 & -.58 & 1.06 & 1.21 & 391.43 & .98 \\
\hline Pulaski, Vir. & 10 & -.00 & 1.00 & .44 & 5408.23 & 1. 00 \\
\hline Martinsville, Vir. & 16 & .02 & 1.00 & 2.37 & 73.98 & .84 \\
\hline Combined Set & 232 & -.16 & 1.01 & 2.33 & 4193.07 & 95 \\
\hline
\end{tabular}




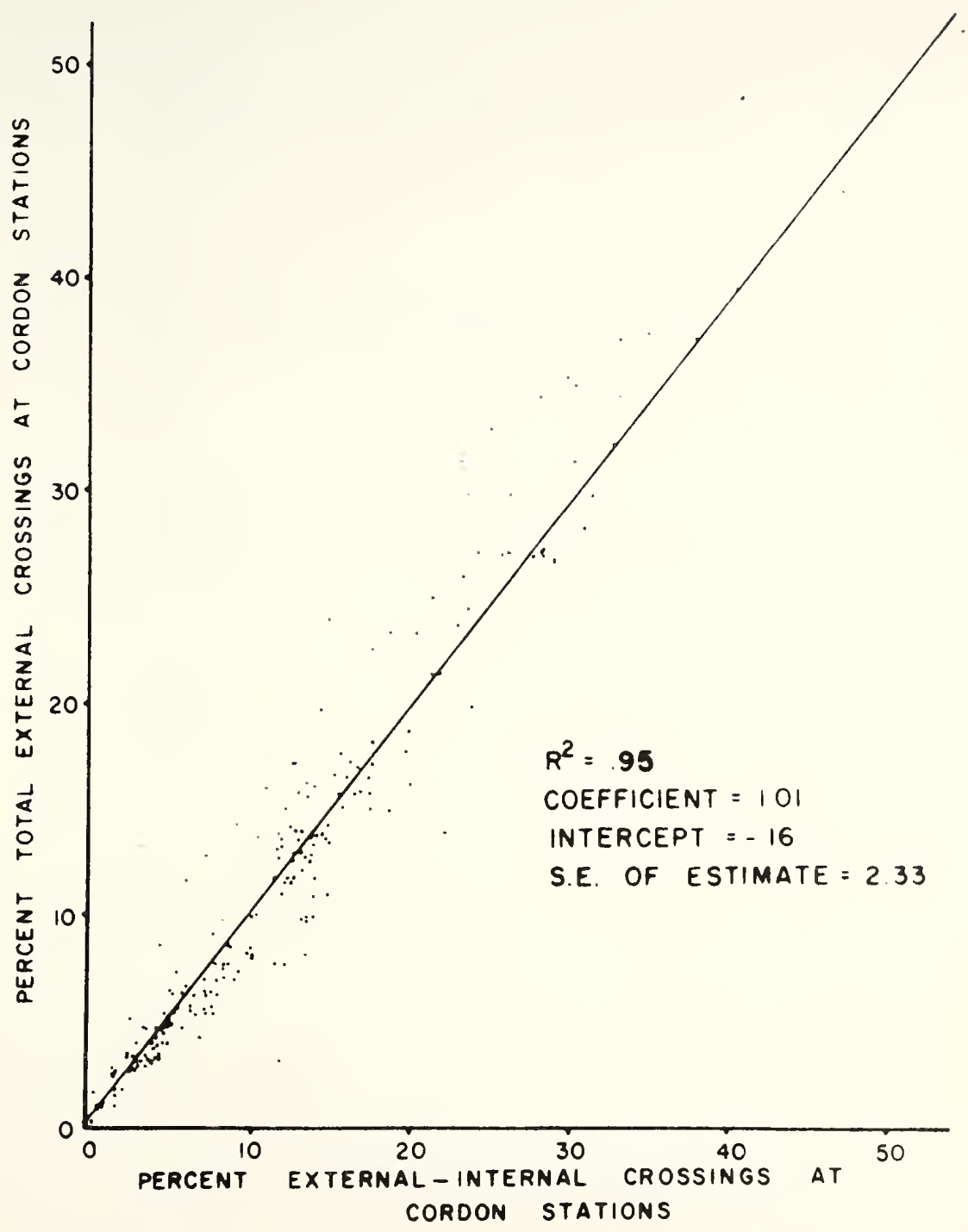

FIGURE 3. PERCENT OF TOTAL EXTERNAL CROSSINGS AT CORDON STATION v8. PERCENT EXTERNAL - IMTERNAL CMOSSMVO AT CONOON STATION 


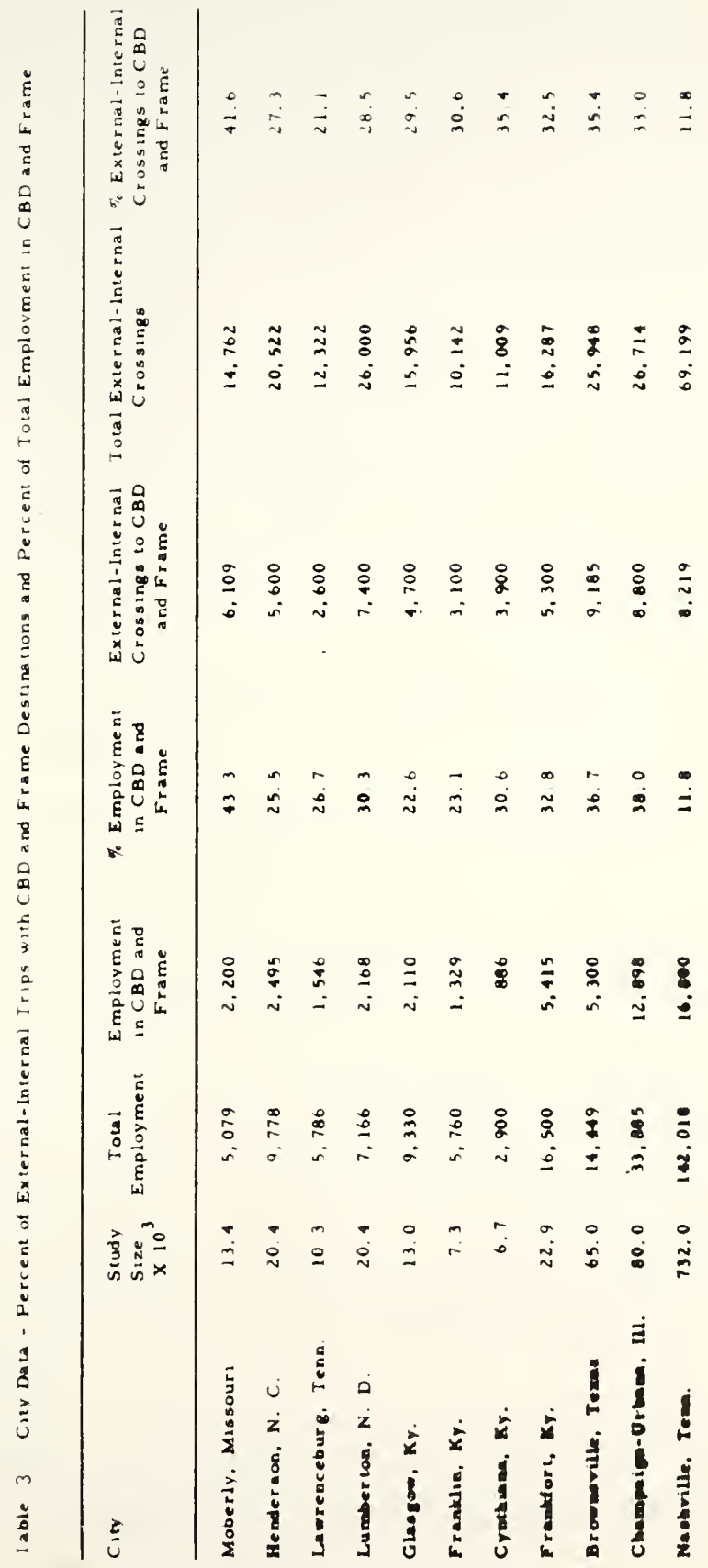


the regression coefficlent was .95 , the standard error of the estimate was 4.60 percent, and the intercept value is 1.11 . The assumption, that the percent of the total external-internal trips with origins and destinations in the Central Area is the same as the percent of the total study area employment employed in the Central Area, was considered valid.

External Survey Report Not Avallable

If an external survey report is not available the following procedure should provide adequate accurate information for planning. The external trip information can be developed by regression modeling. Certain assumptions must be made in addition to those generally required for regression modeling such as:

a. The city must exist as a separate entity, i.e., not as a suburb of a larger clty.

b. A major military establishment or similar trip attractor must not be in the area immediately outside the city.

c. The city must not be located on an international border.

Regression analysis, using cross products of certain combinations of the variables, determined from plots, was employed as a means of investigating the interactions. Possible combinations of independent variables versus each of the response variables were plotted. Those combinations of variables indicating an intersection within the limits of the response variable being investigated, if they met the additional criteria stated above, were then entered into the stepwise regression program by use of the transgeneration option.

External survey reports from seventy-seven cities in nineteen different states were obtained for the original data set. The reports were made avall- 
able by the state highways departments in each of the states.

A total of twenty independent varlables, both quantitative and qualitative, were available in the development of the final regression models for this study. Of these twenty, three were dummy varlables used to represent qualitative factors. Utilizing the same independent variables, two models were developed regressing on two different response varlables during the model development. The response variables were the total external and total external-external cordon crossings. The clties included in the data set are listed in Table 4.

Total External Crossings. As a result of the regression analysis, a model for predicting total external cordon vehicle crossings (for an inference space of 10,000 to 100,000 population) is given below as equation (1).

$$
Y_{1}=28.55+0.068\left(x_{1}\right)+0.00009\left(x_{2}\right)-369.8\left(x_{3}\right)+78.3\left(x_{4}\right)
$$

where:

$$
\begin{aligned}
Y_{1}= & \text { Total external cordon crossings } \\
x_{1}= & \text { County population density (population/square mile) } \\
X_{2}= & \text { County area multiplied-by population of the cities larger } \\
& \text { than subject clty within a } 25 \text { mile radius of the city center } \\
& \text { (population - square miles) } \\
x_{3}= & \text { Reciprocal of the total study area population } \\
x_{4}= & \text { Reciprocal of the total study area employment }
\end{aligned}
$$

The summary table is as follows:

$\begin{array}{ccccc}\text { Variable } & R & R^{2} & \begin{array}{c}\text { Increase } \\ \text { in } R^{2}\end{array} & F \text { value to enter or remove } \\ \mathrm{x}_{1} & .66 & .43 & .43 & 25.68 \\ \mathrm{X}_{2} & .75 & .57 & .14 & 10.47 \\ \mathrm{X}_{3} & .81 & .65 & .08 & 7.39 \\ \mathrm{x}_{4} & .85 & .72 & .07 & 8.13\end{array}$


lable 4 Cilles Iniluded in Study

\begin{tabular}{|c|c|c|c|}
\hline City & State & City Pop. $\left(\times 10^{3}\right)$ & Study Pup. $\left(\times 10^{3}\right)$ \\
\hline Moberly & Missouri & 13.4 & 13.4 \\
\hline Lancaster & Ohio & 32.9 & 324 \\
\hline Belletontaine & Ohio & 11.3 & 11.3 \\
\hline Urbana & Ohio & 11.2 & 112 \\
\hline Xenua & Ohio & 25.4 & 25.4 \\
\hline 1 iffin & Ohio & 21.6 & 21.6 \\
\hline Circleville & Ohio & 11.7 & 11.7 \\
\hline Greenville & Ohio & 12.4 & 12.4 \\
\hline Mount Vernon & Ohio & 13.4 & 13.4 \\
\hline Alpena & Michigan & 14.7 & 17.2 \\
\hline Bay City & Michigan & 49. 1 & 82.3 \\
\hline Glasgow & Kentucky & 10.9 & 13.0 \\
\hline Richmond & Kentucky & 12.5 & 12.5 \\
\hline Bowling Green & Kentucky & 30.5 & 33.2 \\
\hline Frankfort & Kentucky & 18.0 & 22.9 \\
\hline Owensboro & Kentucky & 42.5 & 42.5 \\
\hline Elizabethton & Tennessee & 10.1 & 19.7 \\
\hline Henderson & North Carolina & 12.7 & 20.4 \\
\hline Kingston & North Carolina & 24.8 & 49. 0 \\
\hline Jacksonville & North Carolina & 15.7 & 30.6 \\
\hline Lumber ton & North Carolina & 15.3 & 20.4 \\
\hline Sanford & North Carolina & 11.7 & 16.5 \\
\hline Hays & Kansas & 14.0 & 14.0 \\
\hline Independence & Kansas & 11.5 & 11.5 \\
\hline Pıttsburg & Kansas & 18.7 & 18.7 \\
\hline Borger & Texas & 13.9 & 13.9 \\
\hline Bay City & Texas & 12. 0 & 12.0 \\
\hline Brownwood & Texas & 16.3 & 16.3 \\
\hline Big Spring & Texas & 28. 2 & 28.2 \\
\hline Blytheville & Arkansas & 2.8. 3 & 28.3 \\
\hline Pulaski & Virginia & 11.0 & 13.3 \\
\hline Tuscallosa & Alabama & 61.9 & 73.2 \\
\hline Gainsville " & Georgia & 15.4 & 21.4 \\
\hline Boise & Ida ho & 75.0 & 85.3 \\
\hline Billings & Montana & 61.6 & 620 \\
\hline Great Falls & Montana & 60.0 & 74.7 \\
\hline
\end{tabular}


ANOVA

$\begin{array}{lrrrr}\text { Source } & \text { d.f. } & \text { SS } & \text { MS } & \text { F Value } \\ \text { Regression } & 4 & 4519.11 & 1129.78 & 20.10 \\ \text { Residual } & 31 & 1742.47 & 56.21 & \\ \text { Total } & 35 & 6261.58 & & \end{array}$

The standard error of the estimate $=7.50$.

Allocation of Total External Volumes Between Cordon Stations. This distribution follows the procedure previously outlined.

External-External Volume Total. The total external-external cordon vehicle crossings are computed by use of equation (2) as noted below:

$$
Y_{2}=4.28+0.035\left(x_{1}\right)+0.066\left(x_{2}\right)-0.064\left(x_{3}\right)
$$

where:

$$
\begin{aligned}
Y_{2}= & \text { Total external-external cordon crossings } \\
X_{1}= & \text { Population of the cities larger than subject city within a } \\
& 25 \text { mile radius of the city center } \\
X_{2}= & \text { County population density (population/square mile) } \\
X_{3}= & \text { Population of the cities smaller than subject city within a } \\
& 25 \text { mile radius of the city center }
\end{aligned}
$$

The sumary table is as follows:

$\begin{array}{ccccc}\text { Variable } & R & R^{2} & \begin{array}{r}\text { Increase } \\ \text { on } R^{2}\end{array} & F \text { value to enter or remove } \\ \mathrm{X}_{1} & .73 & .53 & .53 & 37.96 \\ \mathrm{X}_{2} & .82 & .68 & .15 & 15.27 \\ \mathrm{X}_{3} & .86 & .74 & .06 & 7.10\end{array}$

ANOVA

\begin{tabular}{lcccc} 
Source & d.f. & SS & MS & F Value \\
Regression & 3 & 1339.08 & 446.36 & 29.69 \\
Residual & 32 & 481.16 & 15.04 & \\
Total & 35 & 1820.24 & & \\
\multicolumn{1}{c}{ The standard error of the estimate } & $=3.88$.
\end{tabular}




\section{Internal Traffic}

Developing a Growth Factor. A growth factor for each corridor must be established to forecast growth of internal traffic. The factor must adequately represent the growth of all "activities" in the corridor. Corridors commonly contain an agglomeration of land uses, each having a different trip generation rate, therefore, a method of weighting these rates is necessary. The growth factor must reflect the increase, present to target year, of each land use.

The method established to handle the welghting of trip attractiveness of various land uses was to use the percentage of total linked-trips by linked-trip purpose. Th1s information was obtained from a review of available origin-destination study reports. Trip purpose may be related to land uses or other parameters to obtain a relative trip attractiveness. Linkedtrip purpose percentages for auto driver trips for varlous size cities indicates that the percentages are similar for all sizes of cities.

Parameters, easily measured and forecastable, to indicate trip purposes are required. The acres of each type of land have been used in many studies for this purpnse but there are problems inherent with this parameter such as varying densities of development, which make it undesirable.

The total number of employees within the unit of study is a good indicator for work and business trips and were used for the study. This information is available from several sources and is usually listed by business establishments and can be forecasted satisfactorily.

Home trips can be determined by using the number of dwelling units per corridor.

Shopping trips may be determined by using the total number of retail employees. The number of retall employees by corridor can be obtained easiest 
concurrently with collection of the number of total employees necessary for work trips.

Social-recreation trips to clubs, theaters, residential areas etc., are difficult to represent with any single parameter due to their diversity. The three parameters used for work and business, home and shopping trips can be assumed to represent these trips without a separate parameter.

Previous research has indicated that these three parameters were adequate to represent the total trips. This project therefore used total employees to represent work and business-linked trips by corridor, the number of retail employees were used for shopplng-linked trips and the number of dwelling units were used for home-linked trips and other trips to residential areas.

The procedure establishes relative trip production rates for the three parameters in the study area in the following manner. The relative average trip production rate per employee are established by dividing the percent of the total trips to be represented by that parameter by the total employees in the study area. The same procedure would be followed for the remaining parameters. These rates are assumed to remain constant over time and are used in both the base and target year.

The procedure for developing a growth rate by corridor was as follows:

1. The relative trip rates by each parameter are multiplied by the quantity of the parameter in the corridor for the base year and the products are totaled.

2. The procedure is repeated for the target year using forecasted quantities of the parameters.

3. The ratio of the target year sum to the base year sum is the corridor growth factor. 
4. The corridor growth factor multiplied by the base year traffic volume in the corridor gives the forecasted or design volume for the corridor.

Plan Evaluation. The evaluation procedures for alternate plans are well documented by many references such as the National Comittee on Urban Transportation (1). The evaluation is simplified because the extent to which mass transit vehicles will contribute to congestion or its relief is minor in small urban areas. Furthermore, freeway networks are seldom warranted. This leaves improvements to the existing system as the primary solution to traffic problems. The street capacity calculations themselves should provide clues as to where additional needed capacity can be provided with minimum expenditures. The Policy and Procedure Memorandum 21-18, U. S. Department of Transportation, Federal Highway Administration, dated May 13, 1971, for the TOPICS program provides a good guide for methods of upgrading existing facilities.

All traffic assignment procedures require engineering judgment. This proposed simplified procedure requires the same judgment in its application. There will be only a few existing parallel arterial streets to handle the corridor traffic and it can be assumed that traffic can be divided between these streets. Major arterials should always have four moving lanes and this should be sufficient in most cases to handle arterial traffic in small urban areas. It should be remembered that re-evaluation of the plan will be simple under the proposed procedure, therefore, can be easily and quickly repeated any time any substantial variations in forecasted traffic volumes are noted.

The usual procedure for major thoroughfare planning is to make an overall twenty year forecast with five year step or incremental forecasts to 
provide information for establishing project construction priorities and for capital improvement prograns. The simplified procedure should not be an exception to this procedure, quite the contrary, this is one of the strong points of the method. Simplicity and minimum personnel requirements permit re-evaluation on short notice as area development dictates. When unexpected new development occurs a re-evaluation can be quickly accomplished to check proposed plans and provide information for modifications if necessary. The five year incremental forecasts will also preclude errors due to large growth factors.

The "best" plan is that plan that satisfies the people of the community and satisfactorily handles the traffic. Utilizing the simplified procedure described herein adequate information will be developed to provide direction to those charged with the responsibility of developing a plan but it is not intended as "the" cookbook solution. Judgment and assistance of those in the area is not only helpful but is an absolute necessity when developing a plan that will serve the purpose and be acceptable to those it affects. Data Collection. Data collection is grcatly simplified using this procedure. Dwelling unit data and street inventory information are obtained from aerial photographs for the various time periods. Fmployment data are obtained from state employment offices, supplemented by some personal contact. Traffic data are usually available from the state, county or city. Some additional counts may be required. Automobile registrations are available from the state.

Additional information, such as maps, zoning, and land use data are usually available from the city; however, some additional data collection may be necessary. 


\section{DEMONSTRATION OF PROCEDURE}

To properly evaluate the growth factor technique of traffic forecasting requires establishing standards for acceptance. The standard of acceptance for this project was established as the point where the predicted volume was within the range of accuracy that would allow a planner or designer to determine the correct number of lanes, proper location of improvements and proper relative construction priorities for improvements to the major thoroughfare system of a small urban area. In reviewing the described procedure, the reader must not lose sight of the basic advantages and the design constraints for this procedure. It is simple, economical to use, and can be effectively utilized by personnel possessing a minimum of expertise in transportation planning. In short, it is intended to be as simple and inexpensive as possible while still providing the required information.

Major thoroughfare capacities for planning purposes are based on the 1965 Highway Capacity Manual (4). Using the manual, certain ranges of service volumes for the demonstration city were obtained for a thoroughfare assuming the following:

1. A level of service - "C"

2. Population of city - 75,000

3. Peak hour factor -.85

4. Directional spl1t - 60-40

5. Peak hour volume - ten percent of ADT
6. $\mathrm{G} / \mathrm{C}-.45$

7. Lane width - 10-12 feet

8. No parking

9. Twenty percent turns

Using the above assumptions, considered reasonable, gives the following capact ty ranges for major thoroughfares.

4 lane thoroughfare - 12,000 - 15,000 vehicles per day

4 lane with left turn lanes - 15,000 - 19,000 vehicles per day

6 lane thoroughfare - 19,000 - 23,000 vehicles per day 
This indicates that an estimated volume with an error of approximately four thousand vehicles per day, for volumes under nineteen thousand, will not change the basic design of the street. If the estimated volume forecasted during the planning study is just under fifteen thousand vehicles per day for a street which has four lanes, twelve feet wide, no improvements will be recommended. If the volume for the target year actually is between fifteen thousand vehicles per day and nineteen thousand vehicles per day, then some widening may be needed at critical intersections to incorporate left turn lanes. At non-critical intersections, additional green time may be available from the cross-street to accomodate the additional volumes. It is apparent from these figures that the underestimation of future traffic by four thousand vehicles per day of volumes below nineteen thousand would not create a traffic problem for the target year. Over estimation would not involve significant over design unless the estimated volume exceeds approximately nineteen thousand vehicles per day.

The streets on the major thoroughfare system in any urban area should be designed and constructed to four lane minimum standards according to the recommendations of the National Committee on Urban Transportation. Volumes in the range below the basic capacity of a four lane facility therefore do not affect the design in any manner.

\section{Feasibility Demonstration}

The city of Columbus, Indiana was selected as the site to demonstrate the feasibility of the entire package comprising the simplified procedure for major thoroughfare planning in small urban areas.

Study Area. Columbus is a city of approximately 27,000 population. The city is a typical small city that has experienced a steady growth through 
the years. Because of the location at the junction point of several rivers and other small streams the growth has been primarily in the north and east portions of the city rather than concentrically as in many communities.

The completion of Interstate 65 , providing a connecting route from Indianapolis to Louisville, Kentucky and also on the route from Chicago to Florida and other southern states, is the only major change in the highway system in the area during the last twenty years.

A number of major industrial plants such as Cumins Engine and Arvin Industries are located in the city. The city has a higher than average ratio of employment to population due to the heavy industrialization. This effect on trip generation characteristics of the community is to produce a higher percentage of external-internal trips than other comparable sized commities. The city administration and the citizens have long recognized the necessity for sound planning of the future. This progressive attitude is positively indicated by numerous studies and resulting reports on all phases of community development. This abundance of basic material to use for data sources may indicate that the estimated cost for the study should be increased when estimating the cost of application in communities with less basic data.

External Cordon. The study area external cordon was established to include the area expected to become developed by 1990. The Interstate 65 route was utilized as the west cordon limit because of the natural screenline it provides.

Clifty Creek was established as the east boundary. The location of the cordon throughout the study area permitted using the Indiane State Highway Commission count station locations. 
Jones, Grecco

Corridors and Major Thoroughfares. The arterial street plan prepared by DeLeuw Cather and Associates (2), presently being used as a guide for Columbus, was used to assist in infitial street inventory trapic volume counts and corridor identification.

The identiffation of corridors for Columbus was accomplished by utilizing the arterial street plan, the existing traffic volume plow map, existing land use map and information from personnel familiar with the area.

Seven basically radial corridors were established as shown in Figures 4 and 5. Two of these corridors overlap due to the configuration of the streets. State Highway 46 is considered a radial route; however, it effects a ninety degree route change to approach the central area screenline, disbursing traffic over flve closely spaced streets crossing the screenline. This alighment crossed corridor 4, Central Avenue. This does not create a double count because the procedure uses a growth factor not trip productions.

U. S. 31 Bypass traffic was forecasted using a growth factor based on the growth of the entire area from the Tenth Street corridor on the east to the Flatrock River on the west.

Calibration Procedure. The simplified procedure developed recommends the use of two points in time to establish a calibration for the city involved. The profect was inftiated early in 1971, therefore 1970 was used for the study year data.

The 1960 to 1970 calibration period for Columbus was selected for several reasons as follows:

1. U. S. Bureau of Census data was avallable to check dwelling unit counts from aerial photography.

2. Traffic volume counts were avallable from the Indiana State Highway Commission. 


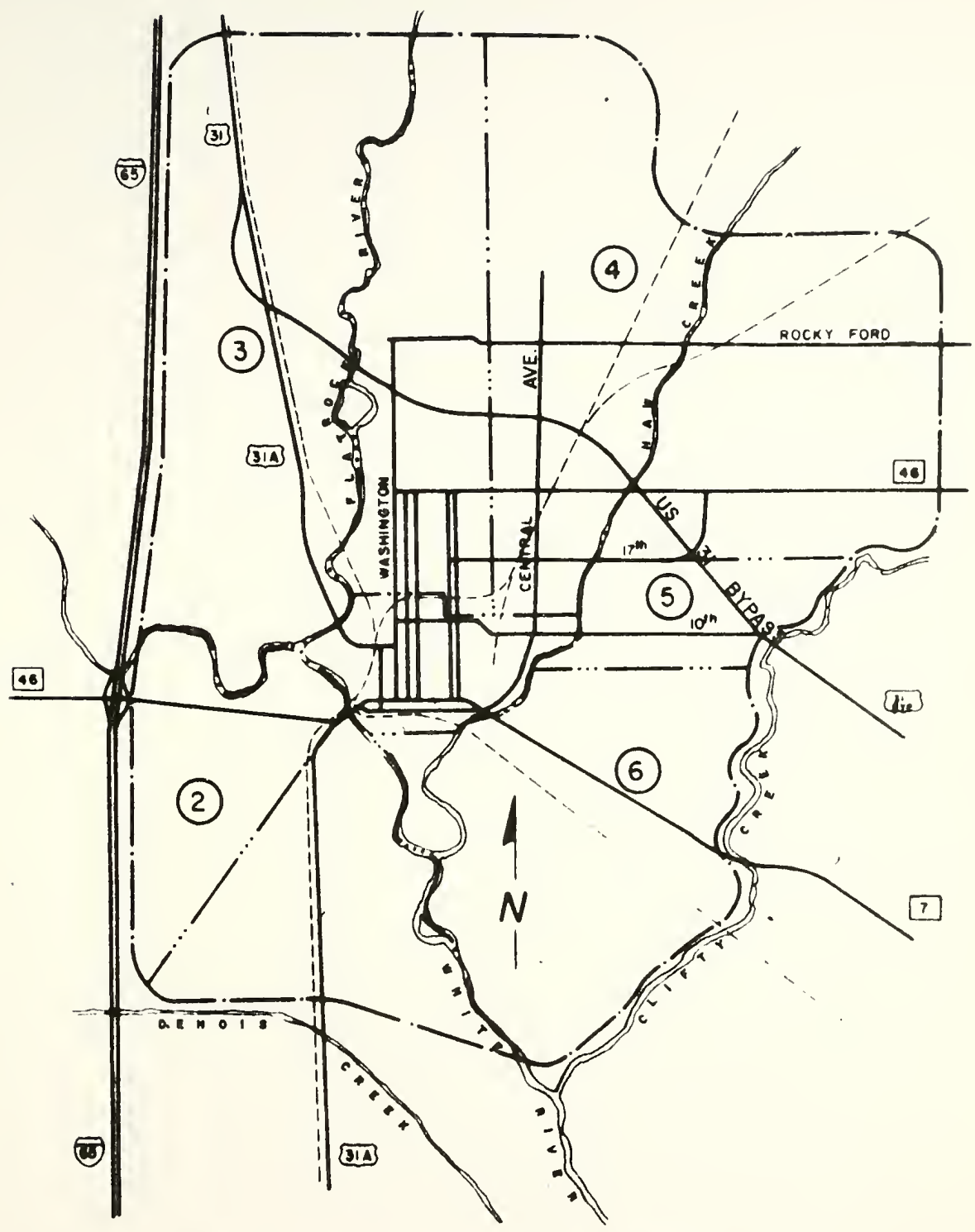

FIGURE 4. CORRIDORS - COLUMBUS 


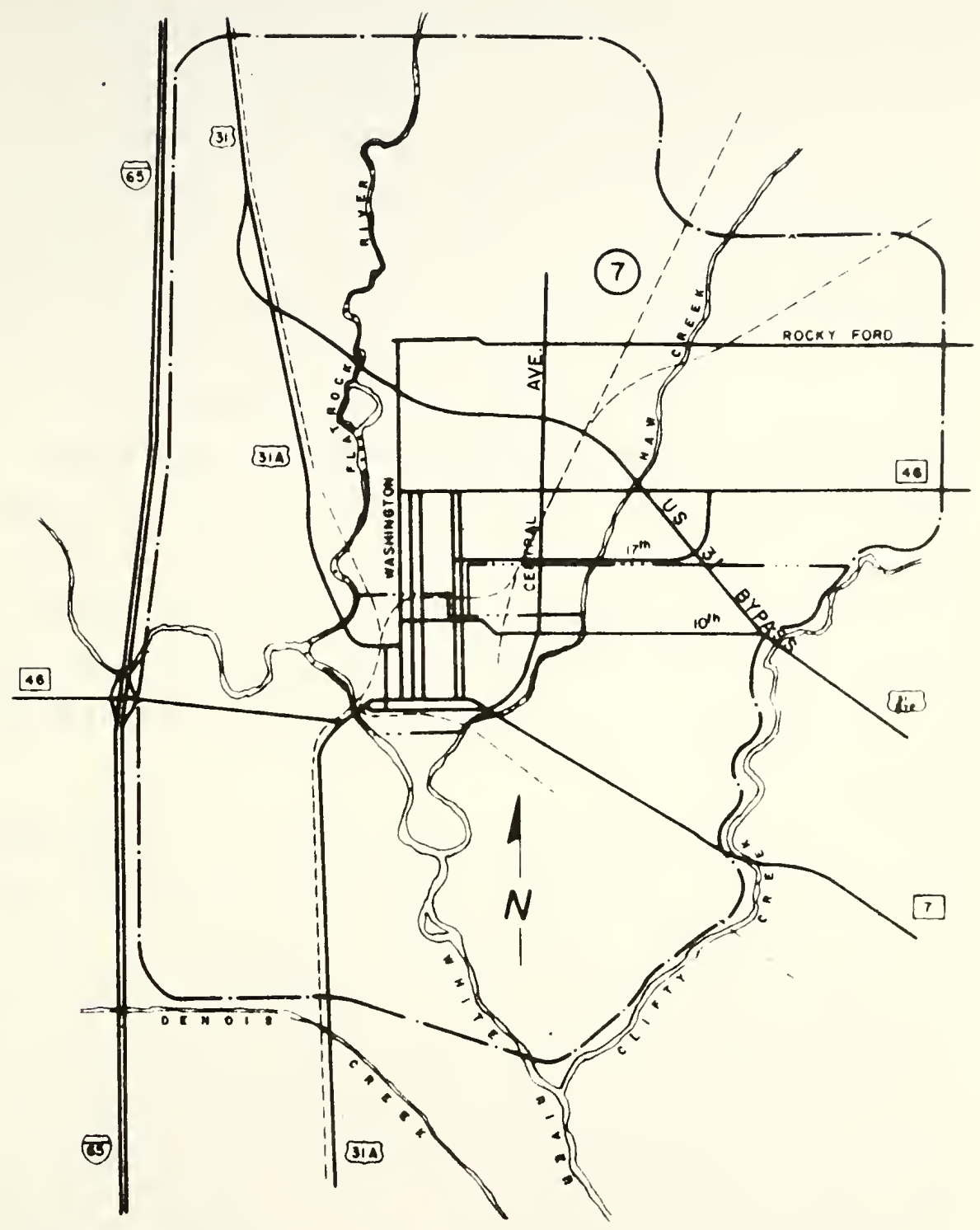

FIGURE 5. CORRIDORS - COLUMBUS 
3. The ten year period provided a reasonable test of the capabilities of the overall procedure.

A complicating or confounding factor that occurred during this period was the construction and opening to traffic of Interstate 65 immediately west of Columbus. The 1963 Columbus Arterial Plan (2) presented before and after volumes throughout the city providing sufficient information to assess the effect of opening of Interstate 65 .

The actual calibration procedure was as follows below. 1960 was used as a base year and growth factors for the external and internal traffic based on the corridors established were computed. After applying the growth factors to the 1960 existing volumes, the resulting forecasted 1970 volumes were compared to the observed 1970 volumes. Comparison of the central area screenline volumes whin the accuracy necessary for design was considered reasonable assurance that the corridors established are satisfactory for planning purposes.

External Traffic. An external traffic growth factor wes computed using the increase in total vehicle registration for Bartholomew County for the period 1960 - 1970. The completion and opening to traffic of Interstate 65 just west of the city in late 1962 make direct comparison of 1960 to 1970 external volumes impossible; however, adjustment of the 1960 volumes on U.S. 31 by thirty percent to adjust for the Interstate provides comparable figures. The adjustment factor was provided by information presented in the Arterial Street Plan report (2).

Table 5 presents the comparison of forecasted 1970 traffic volumes at external cordon stations (developed by applying a growth factor based on the increase in total vehicle registration in the county from 1960 to 1970 , to the 1960 traffic volumes at each station) to the observed 1970 traffic volumes. The 1960 traffic volumes at the U. S. 31 external station north 
Table 5 Columbus - External Cordon Station Check

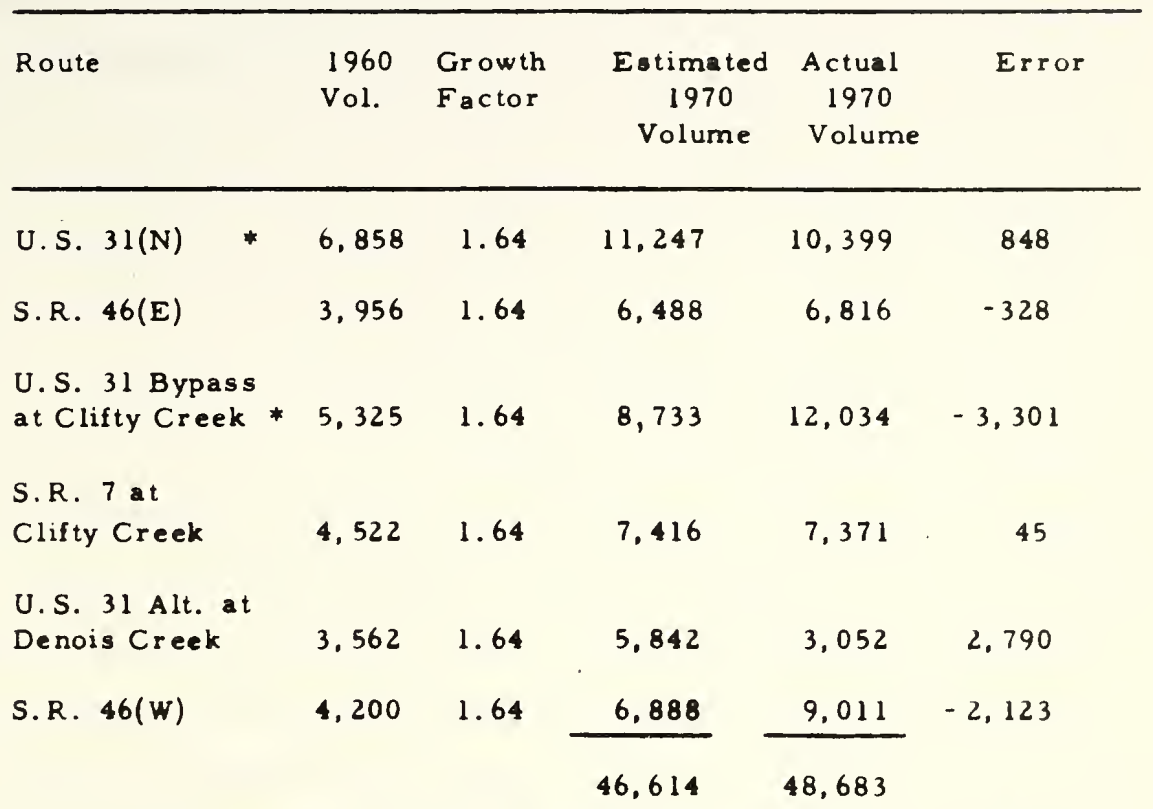

* Existing volumes reduced $30 \%$ to adjust for opening of 1.65 as per Arterial Street Plen for Columbus, Indiana (9). 
of the city and U. S. 31 Bypass at Clifty Creek were reduced thirty percent as Indicated by the DeLeuw Cather Study (2) to adjust for the opening of Interstate 65. The total 1970 forecasted external volume was 46,614 vehicles per day as compared to the observed 1970 external volume of 48,683 vehicles per day at the stations. The total error is 2,069 crossings and by distributing this to the individual stations based on the existing percentages of total external traffic the maximum error would be 500 crossings. Individual expansions at each station indicate maximum errors of 3,301 vehicles per day at U.S. 31 Bypass at CIffty Creek and 2,790 vehicles per day at U.S. 31 AIternate at Denols Creek. These differences can be attributed to a sifght change in traffic patterns occurring subsequent to the opening of Interstate 65. None of the differences were of sufficient magnitude to cause a design change if they were used for a design. However, the future forecast will be based on the 1970 patterns and therefore will not reflect these differences due to a slight change in traffic patterns. The growth factor for all external stations was based on the Bartholomew County total vehicle registration increase because Interstate 65 (outside cordon) was considered to be the route selected by cross state traffic. The comparison thus obtained was considered acceptable and a growth factor based on county vehicle registration increase was considered acceptable for forecasting external volumes to 1990 .

The external-external component of the total external traffic was determined by regression model. The external-external volume thus computed was 9,500 vehicles in 1960 and 10,800 in 1970. This volume was distributed to the external stations using the same percentage as existed for the total external volume. 
Jones, Grecco

The percentage of the external-internal traffic to be distributed to the central area was determined by the percentage of total study area employees employed in the central area in 1970. This amounted to 44.3 percent.

Internal Traffic. The internal traffic volume growth factors were computed using the growth of three parameters of dwelling units, total employment and retail employment in each of the seven established corridors.

The percentage of the total internal trips to be represented by each of the three parameters of dwelling units, total employment and retail employment are 50,35 , and 15 respectively. Dwelling unit data by corridor was obtained from $I^{\prime \prime}=400^{\prime}$ aerial photography enlargements for both years. Employment data for both years were from information assimilated and tabulated by the Indian Employment Securities Division. The base year traffic volumes were basically from counts made by the Indiana State Highway Commission in 1959, supplemented by information from city files and the Arterial Street Plan Report (2). The 1970 counts were from the I.S.H.C. and City Engineer's office. Additional counts were provided by city personnel to complete the required information.

Using the corridor growth factor procedure the existing 1960 traffic volumes were expanded to 1970 and compared to the actual observed traffic volumes. The forecasted and observed volumes at the central area screenline were compared for each corridor and additional point volumes were compared on S.R. 46 (Twenty-fifth Street) at U.S. 31 Bypass and Washington Street intersections. Table 6 presents the results of this comparison and gives the growth factors used.

The maximum difference between 1970 forecasted average dally traffic volumes and 1970 observed volumes was 2,361 in Corridor 3, U.S. $31(N)$. Th1s 


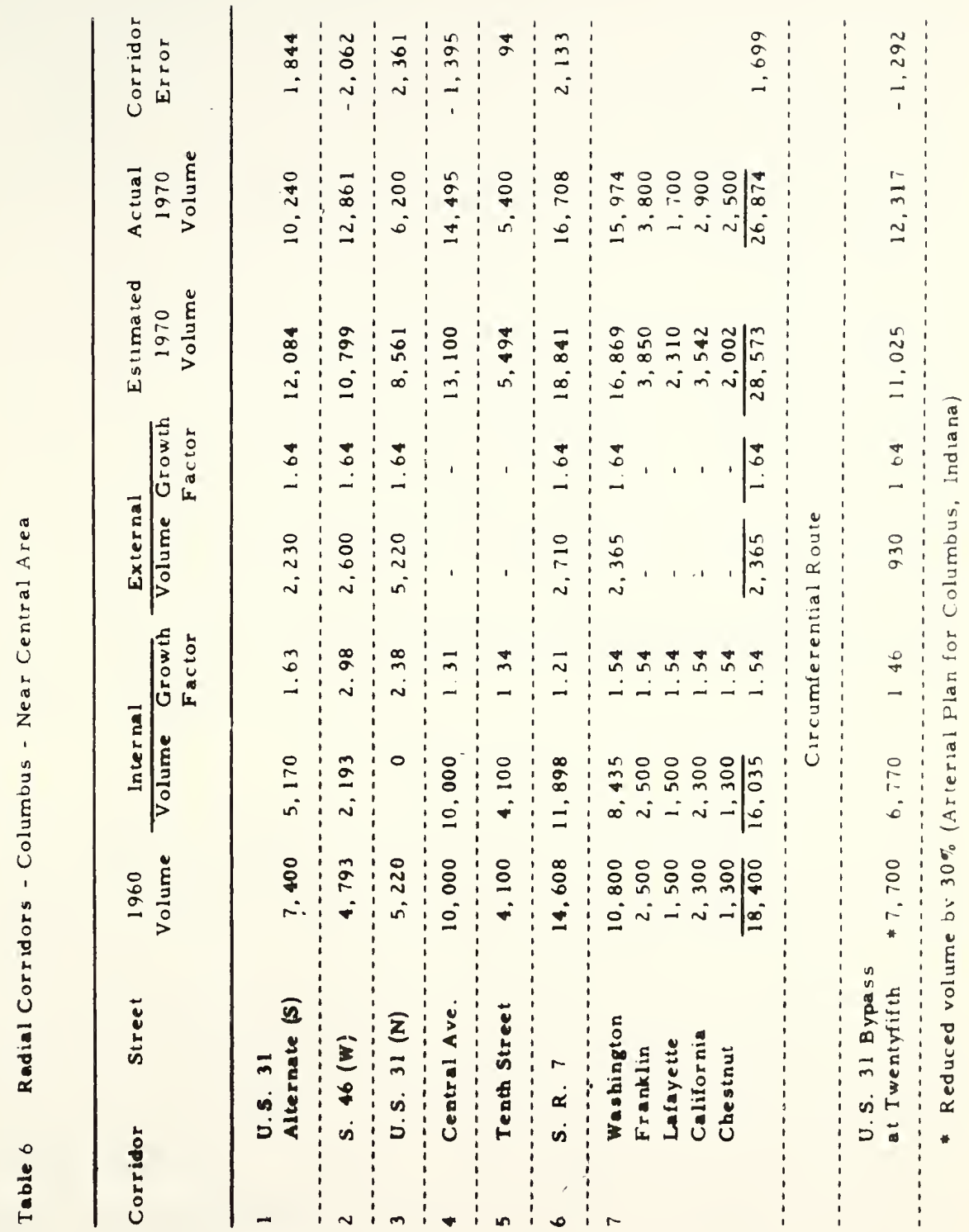


is probably due to a slight change in traffic patterns occurring after completion of Interstate 65 ; however, the difference did not affect the thoroughfare design.

Differences in all other corridors are of such magnitude that designs would have been unaffected. Corridor 7 is one of the major corridors with respect to total traffic magnitude; however, the one-way pairs of Franklin and Lafayette, California and Chestnut, in addition to Washington Street serve the traffic desiring to enter the central area. Seventeenth Street was not included as an east-west route because of its configuration terminating at U.S. 31 Bypass on the east and at a cemetery on the west. It does effectively serve as a overflow or alternate route for S.R. 46 and Twenty-fifth Street for short trips as shown by the existing volumes. The calibration or check period as described herein substantiates the corridor identifications and the overall feasibility of the entire procedure with respect to providing adequate accurate design information.

\section{CONCLUSIONS}

The completed package for a simplified planning procedure for major thoroughfare planning for small urban areas, utilizing the corridor growth factor technique with synthetically developed external data, provides traffic volumes sufficiently accurate to develop major thoroughfare plans. The methodology fits satisfactorily into the overall planning process utilizing output from other studies as input to the process. The cost of completing this type of study is a fraction of that required for the home-interview, computer oriented procedures although the resulting information produced satisfies the same requirements, i.e., design volumes. Detalled cost and time figures were compiled during the feasibility demonstration. After making 
Jones, Grecco

upward adjustments in these costs to convert from a research environment, the best estimate of the total cost if the study is conducted by city personnel is $\$ 15,389$.

Specifically the following conclusions can be drawn from the research.

1. The corridor growth factor procedure, in combination with synthetically produced external information, can be used as a complete package to determine future traffic demand within the accuracy necessary for major thoroughfare planning in small urban areas. Tests in Columbus substantiated this fact.

2. The three parameters used for the corridor growth factors determination are adequate to inlicate corridor traffic volume prowth. The data are easy to obtain and easy to forecast. Aerlal photography can be used satisfactorily to obtain dwelling unt information, discern growth patterns, etc., for use with the simplified procedure.

3. The research indicates that the following conclusions may be drawn concerning external traffic in small urban areas:

a. The existing distribution of total external cordon traffic volumes between stations may be used as the best estimate of future distribution of the forecasted total external volumes.

b. For small urban areas, a growth factor developed using the county total vehicle registration increase is sufficiently accurate for thoroughfare planning.

c. Regression modeling can be used to provide the total externalexternal traffic volumes in a small urban area within sufficient 
accuracy for thoroughfare planning and this computation does not require computer usage.

d. The best estimate for distribution of external-external traffic volumes among external cordon stations is the existing percentages of total external volumes.

\section{ACKNOWLEDGMENT}

The authors wish to acknowledge the financial support of the Joint Highway Research Project of Purdue University and Indiana State Highway Commission $(5,6,7,8)$, and the Federal Highway Administration. Also the data assistance provided by many State Highway Departments is greatly appreciated. 
1. Better Transportation for Your City, National Committee on Urban Transportation, Public Administration Service, Chicago, Illinois, 1958.

2. DeLeuw, Cather and Company, Arterial Street Plan for Columbus, Indiana, Chicago, Illinois, April $196 \overline{3}$.

3. French, D. K., "A Simplified Procedure for Major Thoroughfare Planning in Small Urban Areas", Joint Highway Research Project, Report No. 29, November, 1967.

4. Highway Research Board, H1ghway Capacity Manual, Special Report No. 87, 1965.

5. Jones, Andrew D., A Simplified Procedure for Major Thoroughfare Planning in Small Urban Areas, Joint Highway Research Project, July 1972, Report No. 18 .

6. Jones, Andrew D., Study Design for Columbus, Indiana, Major Thoroughfare and Plan Development Study, Joint Highway Research Project, July 1972, Report No. 19.

7. Jones, Andrew D., Major Thoroughfare Study and 1990 Plan for Columbus, Indiana, Joint H1ghway Research Project, July 1972, Report No. 20.

8. Jones, Andrew D. and W. L. Grecco, Procedure Manual for Determining Traffic Patterns for a Simplified Procedure for Major Thoroughfare Planning in Small Urban Areas, Joint Highway Research Project, July 1972, Report No. 21. 
